\title{
A Trust Evaluation Model for Social Commerce Based on BP Neural Network
}

\author{
Lei Chen ${ }^{1,2}$, Ruimei Wang1* \\ ${ }^{1}$ School of Economics and Management, China Agricultural University, Beijing, China \\ ${ }^{2}$ School of Information, Beijing Wuzi University, Beijing, China \\ Email: *wangruimei@cau.edu.cn
}

How to cite this paper: Chen, L. and Wang, R.M. (2016) A Trust Evaluation Model for Social Commerce Based on BP Neural Network. Journal of Data Analysis and Information Processing, 4, 147-158. http://dx.doi.org/10.4236/jdaip.2016.44013

Received: July 21, 2016

Accepted: October 10, 2016

Published: October 13, 2016

Copyright $\odot 2016$ by authors and Scientific Research Publishing Inc. This work is licensed under the Creative Commons Attribution International License (CC BY 4.0). http://creativecommons.org/licenses/by/4.0/ (c) (i) Open Access

\begin{abstract}
Recent years we have witnessed the rapid growth of social commerce in China, but many users are not willing to trust and use social commerce. So improving consumers' trust and purchase intention has become a crucial factor in the success of social commerce. Business factors, environment factors and social factors including twelve secondary indexes build up a social commerce trust evaluation model. Questionnaires are handed out to collect twelve secondary indexes scores as input of BP neural network and composite score of trust as output. Model simulation shows that both training samples and test samples have low level of average error and standard deviation, which certify that the model has good stability and it is a good method for evaluating social commerce trust.
\end{abstract}

\section{Keywords}

Social Commerce, Trust Evaluation, Trust, BP Neural Network, Evaluation Model

\section{Introduction}

Social commerce is a kind of electronic commerce mode that integrates social media and online shopping together. Users of a social commerce website can share shopping experience and interests with each other, obtain useful information of the goods or services, and get more preferential and reasonable price to buy goods and services of high quality by referencing to others' recommendation, evaluation and interactive discussion. Now social commerce in China has become an overriding electronic business model that cannot be ignored and aroused wide attention of scholars.

According to the survey data released by China Internet Network Center (CNNIC), although the network users paid more on social shopping in recent years, the willing- 
ness to share shopping information and to buy other people's recommendation were low. Respectively $64.4 \%$ and $67.7 \%$ of the online shopping users did not want to share the shopping information and buy other people's recommended products [1]. This certified that lack of trust led to low acceptance of social commerce, and the consumers generally worried about the safety of trading information and reliability of other people's online evaluation. This paper tries to set up an index system to describe factors that influence consumer trust in order to help consumers' objective evaluation and selection of social commerce websites, and help the businessmen to understand consumers' demand and improve service quality.

The research on social commerce trust mostly includes the formation mechanism and the influence factors of establishing consumers' trust. Trust in these studies is deemed as a potential variable to measure consumer cognition, which is always indirectly expressed through its impact factors, purchase and adoption intention. Consumers need direct indicators to evaluate whether a social commerce website is trustworthy. This paper builds a social commerce trust evaluation model by using principle of BP neural network from the perspective of consumers, to provide a solution for the evaluation of social commerce trust.

Trust evaluation of electronic commerce is generally used to measure the degree of trust. The consumers' trust on the sellers or the website is not a simple issue of trust or distrust, but a problem of trust degree to which consumers trust on the sellers and online shop, so trust degree stands for quantitative value or level of trust. In electronic commerce, the quantification and classification for consumers' trust are effective ways to measure consumers' perception of trust and also help sellers to improve service. Trust evaluation is a complex process, $\mathrm{Hu}$ and Wang summarized methods used to evaluate degree of trust, including: Analytic Hierarchy Process (AHP), probability theory method, fuzzy set evaluation method, evaluation method based on cloud model, grey clustering evaluation method and BP neural network evaluation method [2]. Jøang used probability theory and fuzzy evaluation method to evaluate the degree of trust in electronic commerce to describe the fuzziness and uncertainty of trust [3]. The probability theory and fuzzy evaluation methods need a large number of empirical data consistent with classical probability distribution; unqualified data will lead to inefficacy in the evaluation. Zhang Jingan and Li Zhengtao built network trust evaluation models of e-commerce based on P2P network and network security using cloud model theory [4] [5]. Fan Lijie et al. used gray prediction theory to solve the problem of trust evaluation in mobile e-commerce, but the gray prediction model failed to avoid false or malicious evaluation, and the process of calculation was complex and tedious [6].

As a widely used neural network model, BP neural network is a kind of nonlinear dynamics system which simulates the human brain to identify, recognize and process information. A BP neural network model can learn and store a large number of inputoutput mapping relationships, extracting rules and learning inherent law of data constantly through learning the training samples. And the biggest advantage is that it avoids the complicated mathematical deduction in the process of model simulation and 
calculation. $\mathrm{Hu}$ and Jiang made a comparative study on the trust evaluation methods of e-commerce, and finally built a C2C e-commerce trust evaluation model by use of BP neural network [7].

This paper tries to establish an index system for consumers' trust evaluation of the social commerce platform based on the influence factors of consumers' trust for social commerce. A neural network simulation model is established to evaluate consumers' trust by collecting the user ratings records as the training of the data. The model provides a quantitative method for the comprehensive evaluation of consumers' trust of the social commerce platform.

\section{Principle of BP Neural Network}

The BP neural network is a kind of typical multilayer feedforward neural network that simulates the human brain learning process. When the signal is transmitted within the neural network, the input signal is transmitted from the input layer to the output layer through the hidden layer. Each layer is composed of a number of neurons and neurons in the same layer will only affect those in the next layer. If the output layer does not get the desired output, the error signal will be transmitted in the opposite direction, and the weight and threshold value of the network will be computed again until the expected output is close to the desired output.

A typical BP neural network topology is shown below (Figure 1).

$\mathrm{BP}$ neural network is a function expressing nonlinear relation. In a BP neural network, $x_{1}, x_{2}, \cdots, x_{n}$ represent input values, $y_{1}, y_{2}, \cdots, y_{m}$ stand for output values (predicted values). The connection weights of different neurons between the input layer and hidden layer are expressed by $w_{i p}$ and the connection weights between the hidden layer and the output layer are expressed by $w_{j k}$. If a BP neural network has a number of $\mathrm{n}$ input nodes and $\mathrm{m}$ output nodes, the network represents a set of mapping relationship from $n$ independent variables to $m$ dependent variables. The input data need to be trained in the neural network firstly, and the training process usually consists of the following seven steps:

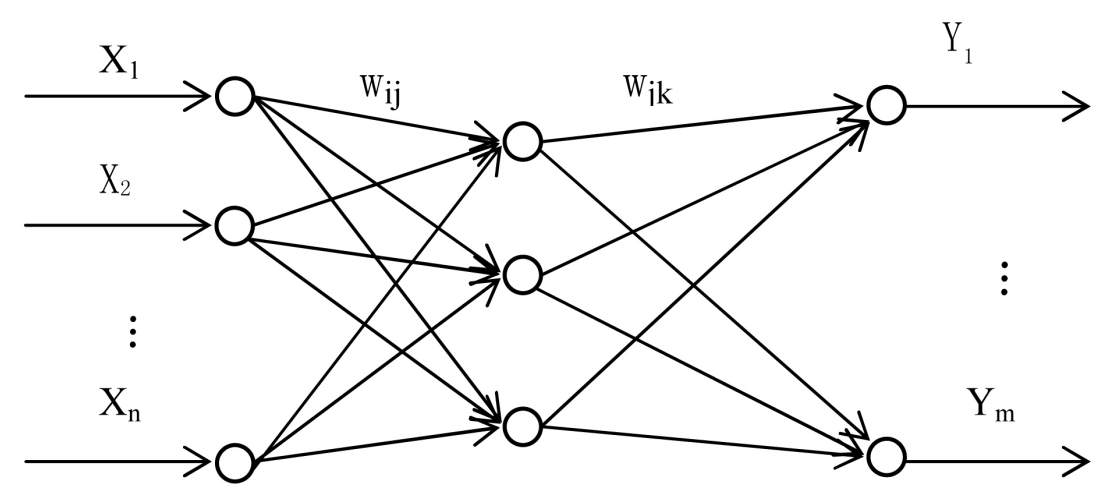

Input Layer Hidden Layer Output Layer

Figure 1. A BP neural network topology. 
Step 1: Network Initialization.

The number of neurons of the input layer $\mathrm{n}$ is determined by the input value of training sample data $\mathrm{X}$, and the number of neurons of the output layer is determined by the output value of training sample data $Y$. The number of neurons in the hidden layer can be determined according to the empirical formula. Network initialization includes initialization of the hidden layer's threshold $a$ and the output layer's threshold $b$ to determine the learning rate and the transfer function.

Step 2: Output Calculation of Hidden Layer

The hidden layer output $H$ is computed by formula (1), $l$ is the number of nodes in the hidden layer, $f$ is the transfer function of implicit layer which must be a differentiable linear function or a nonlinear function. Sigmoid function is the most commonly used function.

$$
\begin{gathered}
H_{j}=f\left(\sum_{i=1}^{n} w_{i j} x_{i}-a_{j}\right), \quad j=1,2, \cdots, l \\
f(x)=\frac{1}{1+\mathrm{e}^{-x}} \quad(0<f(x)<1)
\end{gathered}
$$

Step 3: Output Calculation of Output Layer

BP neural network forecast output $O$ is computed according to the hidden layer output $H$, the connection weights $w_{j k}$ and the threshold value $b$.

$$
O_{k}=\sum_{j=1}^{l} H_{j} w_{j k}-b_{k}, \quad k=1,2, \cdots, m
$$

Step 4: Calculation of Error

The network prediction error $e$ is computed according to the neural network predicted output $O$ and desired output $Y$.

$$
e_{k}=Y_{k}-O_{k}, \quad k=1,2, \cdots, m
$$

Step 5: Update Weight

The network connection weights $w_{i j}$ and $w_{j k}$ are updated according to the network prediction error $e . \eta$ stands for learning rate.

$$
\begin{gathered}
w_{i j}=w_{i j}+\eta H_{j}\left(1-H_{j}\right) x(i) \sum_{k=1}^{m} w_{j k} e_{k}, i=1,2, \cdots, n ; j=1,2, \cdots, l \\
w_{j k}=w_{j k}+\eta H_{j} e_{k}, \quad j=1,2, \cdots, l ; k=1,2, \cdots, m
\end{gathered}
$$

Step 6: Update Threshold Value

Threshold value of the network nodes $a$ and $b$ are updated according to the network prediction error e.

$$
\begin{gathered}
a_{j}=a_{j}+\eta H_{j}\left(1-H_{j}\right) \sum_{k=1}^{m} w_{j k} e_{k}, \quad j=1,2, \cdots, l \\
b_{k}=b_{k}+e_{k}, \quad k=1,2, \cdots, m
\end{gathered}
$$

Step 7: Update Threshold Value

Determine whether the iteration of the algorithm is over, if not, return to step 2.

\section{Trust Evaluation Index System of Social Commerce}

Literatures [8]-[13] studied factors that influencing consumers' trust and acceptance in 
the context of social commerce, covering three aspects including the business environment, network transaction environment and social media characteristics. Previous research showed that the trust degree is high if the websites and businesses had good reputation, providing satisfactory services, secure network trading environment and the third party security mechanism, and ensuring that information was true and reliable. All these factors can be induced to three first level indicators, which will be further refined to build a complete index system.

\subsection{Index System Construction}

1) Business Factors

The preliminary study on consumers' trust for traditional e-commerce have shown that a business's good reputation had significant positive effects on building and enhancing consumer's trust, and sellers' better pre-sales, after-sales service, can increase the user's trust. American Cheskin Research published six dimensions of trust in electronic commerce including reputation. Nonprofit research institute Consumer WebWatch put forward five dimensions of consumers' trust including service.

Therefore the businessman's reputation and service are very important factors affecting consumers' trust, and they will definitely be incorporated in the trust evaluation model as two second level indicators.

2) Environmental Factors

Social commerce environment factors include sense of fun, usefulness, ease of use, website quality, privacy and security, and institutional guarantee.

By participating discussion, interacting with others and sharing products information, consumers are able to experience the fun of online shopping. So sense of fun is a big difference between social commerce and the traditional electronic commerce, because perceived interest can promote consumers' trust. Ease of use means that the consumers think a social commerce website is helpful for online shopping, having good compatibility and lower transformation cost. Liang and Li's research suggested that website quality had a significant impact on the consumer's continuous use of social commerce websites. In addition, the security measures for user's privacy and transaction, and a sound institutional guarantee will enhance consumer's trust [14].

3) Social Factors

In traditional e-commerce environment, consumers make purchase decisions mainly relying on subjective perception and historical transaction records. While in social commerce environment, consumers' purchase decision is not only affected by sellers and trading environment, but also influenced by social factors including social participation, social interaction, social recommendation and social identity. In social commerce environment, consumers are the center of social commerce activities. Social media promotes the interaction between consumers and businesses, consumers and consumers, and consumers are willing to share their shopping information and use experience on the social media. Social participation and interaction help them to find and buy good products at low price. Consumers with the common interest are easy to form 
a group and obtain sense of belonging and social identity, and they are easy to be affected by community discussions, online friends (opinion leaders, friends, strangers' comments, etc.) during online shopping. Information recommendation based on social network relationship improves the degree of consumers' trust, and will promote online shopping behavior in the strong relationship network.

The index system of social commerce trust evaluation is shown in Table 1.

\subsection{Sample Collections}

As social commerce is a new mode of e-commerce, users are mostly young people who have rich experience in online shopping or active users of social networks. Sample data are collected through an online survey. 236 questionnaires were answered by people under 40 from different stratums including different education background, level of income, gender and other demographics variables. After deleting the responses that give the same answers for all the questions and who have no social commerce experience, 201 effective questionnaires are finally available.

In order to help the respondents to fully understand all the indicators, this survey designed two or three questions for each second level indicator. 7-point Likert scales are used to measure the degree of agreement from low to high $(1-7)$ for each question. The score of each second level indicator is the arithmetic mean of all the questions of the indicator, and all the scores of 12 indicators are used for input of the BP neural network. The arithmetic mean of score for comprehensive trust degree questions is expected output of BP neural network.

Part of the training sample and test sample data are shown in the following Table 2.

Table 1. Index system of social commerce trust evaluation.

\begin{tabular}{lc}
\hline First Level Indicators & Second Level Indicators \\
\hline Sellers Factors & Reputation $\left(x_{11}\right)$ \\
& Service $\left(x_{12}\right)$ \\
Environmental Factors & Sense of fun $\left(x_{21}\right)$ \\
& Usefulness $\left(x_{22}\right)$ \\
& Ease of use $\left(x_{23}\right)$ \\
& Website quality $\left(x_{24}\right)$ \\
& Privacy and security $\left(x_{25}\right)$ \\
& Institutional guarantee $\left(x_{26}\right)$ \\
& Social participation $\left(x_{31}\right)$ \\
& Social interaction $\left(x_{32}\right)$ \\
& Social recommendation $\left(x_{33}\right)$ \\
& Social identity $\left(x_{34}\right)$ \\
\hline
\end{tabular}


Table 2. Trust degree score of sample data.

\begin{tabular}{ccccccccccccc}
\hline$x_{11}$ & $x_{12}$ & $x_{21}$ & $x_{22}$ & $x_{23}$ & $x_{24}$ & $x_{25}$ & $x_{26}$ & $x_{31}$ & $x_{32}$ & $x_{33}$ & $x_{34}$ & TRU \\
\hline 6 & 3 & 7 & 6 & 6 & 6 & 3 & 4 & 5 & 5 & 1 & 5 & 3.67 \\
5 & 3 & 5 & 4 & 4 & 3 & 3 & 3 & 4 & 3 & 2 & 5 & 3.33 \\
6 & 5 & 5 & 5 & 5 & 4 & 4 & 6 & 6 & 5 & 3 & 5 & 4.33 \\
7 & 6 & 6 & 5 & 6 & 7 & 5 & 7 & 6 & 5 & 6 & 7 & 6 \\
1 & 1 & 6 & 4 & 4 & 5 & 4 & 4 & 6 & 5 & 6 & 5 & 4.67 \\
3 & 3 & 6 & 6 & 5 & 4 & 7 & 4 & 5 & 5 & 3 & 3 & 3.33 \\
6 & 5 & 5 & 5 & 3 & 5 & 6 & 3 & 6 & 4 & 6 & 7 & 5.33 \\
7 & 7 & 7 & 6 & 3 & 6 & 6 & 6 & 7 & 5 & 4 & 5 & 4.67 \\
5 & 5 & 7 & 6 & 4 & 5 & 5 & 6 & 7 & 6 & 5 & 4 & 4 \\
5 & 5 & 6 & 5 & 5 & 5 & 4 & 5 & 7 & 7 & 4 & 5 & 5 \\
2 & 2 & 2 & 2 & 2 & 3 & 5 & 5 & 5 & 5 & 4 & 4 & 4.67 \\
5 & 3 & 7 & 3 & 7 & 5 & 5 & 5 & 3 & 5 & 1 & 5 & 2.67 \\
1 & 2 & 2 & 3 & 1 & 2 & 3 & 2 & 3 & 2 & 2 & 3 & 3.333 \\
3 & 2 & 4 & 6 & 4 & 2 & 4 & 2 & 3 & 2 & 2 & 1 & 2.67 \\
4 & 3 & 4 & 4 & 1 & 2 & 3 & 2 & 5 & 4 & 4 & 5 & 4.33 \\
\hline
\end{tabular}

\section{Research Model}

\subsection{Design BP Neural Network Structure}

There are 12 nodes in the input layer corresponding to the users' score for 12 indicators. A comprehensive trust evaluation value, which is expressed as one node in the output layer, will be computed according to the 12 indicators. The number of neurons in hidden layer needs to be determined based on experience and repeated experiments, because increasing the number of neurons can improve the accuracy of network mapping, but it may lead to longer training time. The usual practice is to refer to empirical formulas to calculate the estimated value of the hidden layer neurons.

$$
\mathrm{l}=\sqrt{n+m}+a
$$

1 represents the number of neurons in the hidden layer, $m$ and $n$, respectively, stand for the number of neurons in the output layer and the input layer, and a is an arbitrary constant ranging from 0 to 10 .

According to the empirical formula, the number of neurons in the hidden layer range from 5 to 13. Finally, when the number of neurons in the hidden layer is 6 , the network error is the least and the performance of the network is better. So the selected neural network structure is $12 \times 6 \times 1$.

\subsection{Pre-Process Input and Output Data}

Before data training, the input data and output data need to be normalized to avoid large network prediction errors due to the different order of magnitude between input data and output data. Function mapminmax of Matlab software is chosen to normalizing the output data and input data to values between -1 and 1.180 sample data are 
randomly selected from 201 sample data as training data, and the remaining 21 data are used for test data.

\subsection{Create and Train Neural Network}

The hidden layer and output layer use Tan-Sigmoid transfer function and LM optimization algorithm (trainlm function) for network learning. The number of network training ware set for the 2000 times, the accuracy of the error is set for 0.015 , and the learning rate is 0.05 . The predetermined accuracy is achieved after 13 times of training, and the best validation performance is met at epoch 6. A neural network model based on direct indicators reflecting consumers' trust is built and part of data are trained in the neural network, the training results are shown in Figure 2.

\subsection{Network Simulation and Output Forecast}

After finishing network learning, the BP neuron network model was set up. Based on the model, the network simulation output was obtained when using training sample data as input of simulation function. And then the output was normalized to get the fitted value of training data.

The simulation ability of a model is usually measured by the difference between the fitted output value and the expected output value. The difference is smaller, the weights and thresholds of model are better, which means the simulation ability of the model is better. Figure 3 showed model fitting comparison curve of expected output and simulation output by calling plot function. The hypothetical conditions were set as follows: The model fitted well if the absolute value of the difference between the expected output value and the simulated output value is less than 0.2. Because the accuracy of model

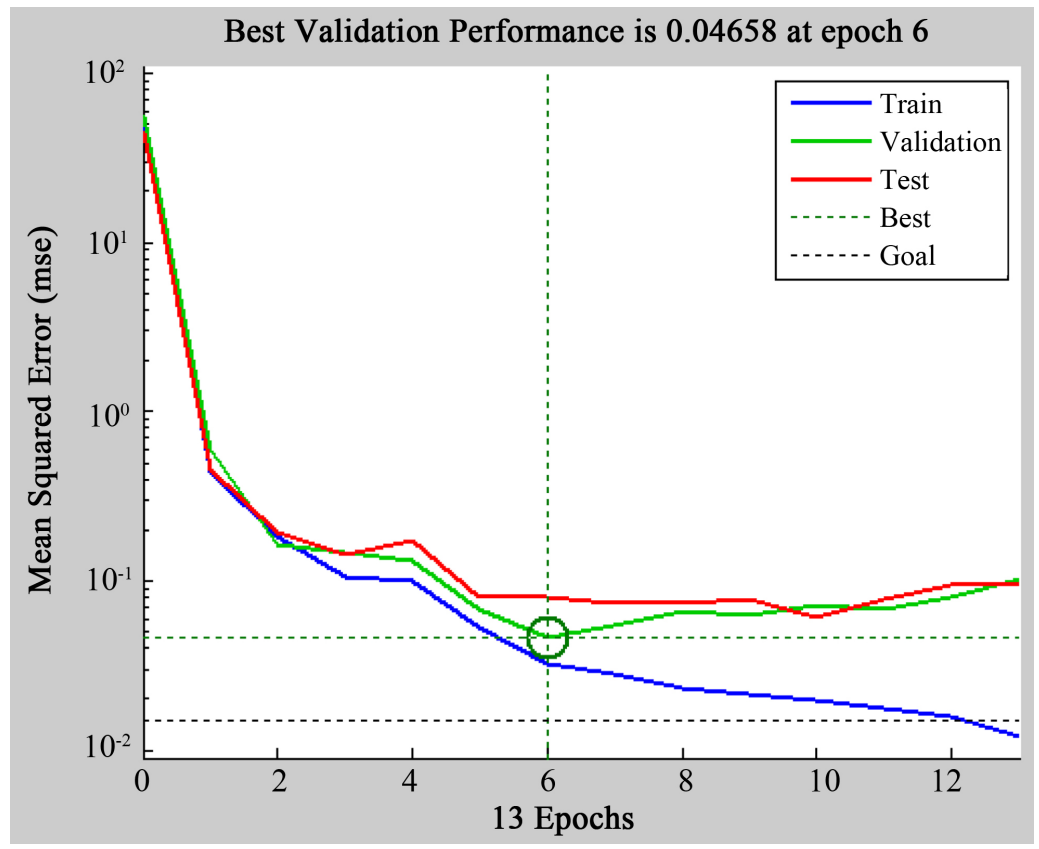

Figure 2. Network training result. 


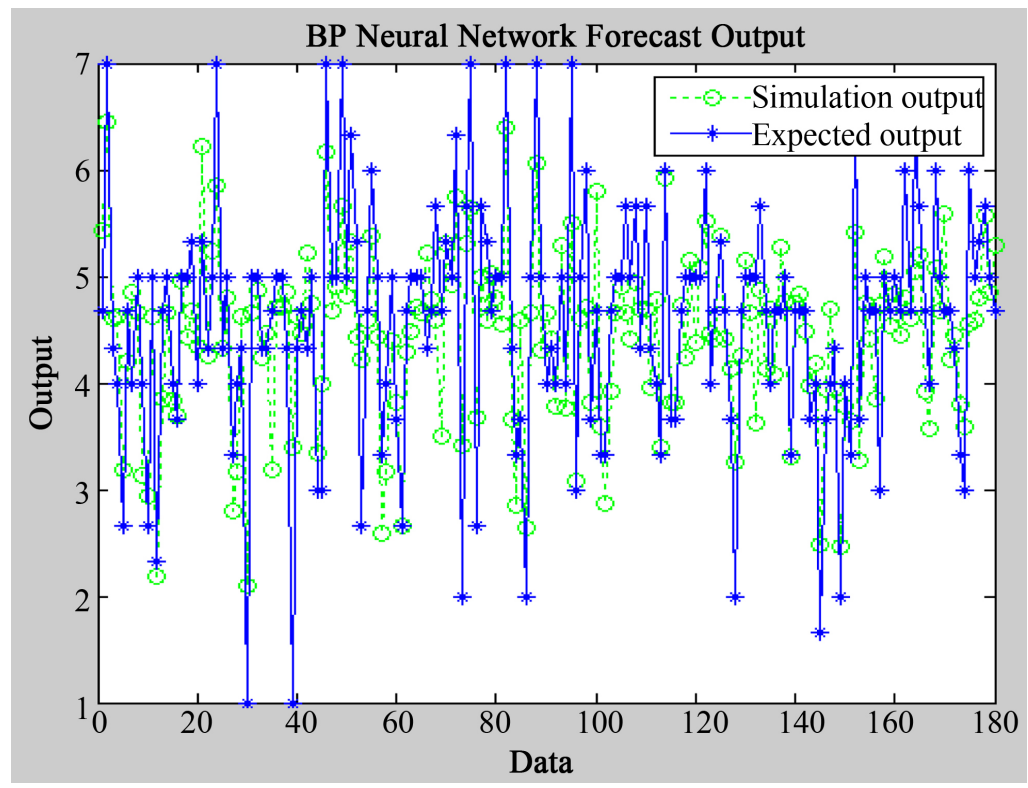

Figure 3. Network simulation output.

simulation is $83.33 \%$, it can be considered that the simulated values are in good agreement with the actual values.

\subsection{Network Test and Model Verification}

After finishing model simulation ability validation, 21 test samples are put into the model in order to further test the model simulation performance. The prediction results (network output) and expected values are shown in the following Figure 4.

Also the hypothetical conditions were set as: the model fitted well if the absolute value of difference between the expected output value and the simulated output value is less than 0.2 , the accuracy of model simulation is $77.22 \%$. It can be seen that there is a certain deviation between the predicted value and the simulation value, but within the acceptable range.

\subsection{Error and Standard Deviation}

After network training and simulation, the difference between the predicted output and the expected output is called error of the model, and the size of error determines the quality of the model. Assuming that the analog output of BP neural network is output_y, observed_x is sample observation value used for input of network. output_y is obtained by the following function:

$$
\text { output_ } \mathrm{y}=\operatorname{sim}(\text { net, observed_ } \mathrm{x} \text { ) }
$$

The relative error is obtained by the following function:

$$
\text { error }=\left(\text { output }_{-} \mathrm{y} \text { - observed _ } \mathrm{y}\right) / \text { observed }_{-} \mathrm{y}
$$

Usually the absolute value abs(error) is used because the error may be positive or negative. The standard deviation of relative error is calculated by STD (error). 


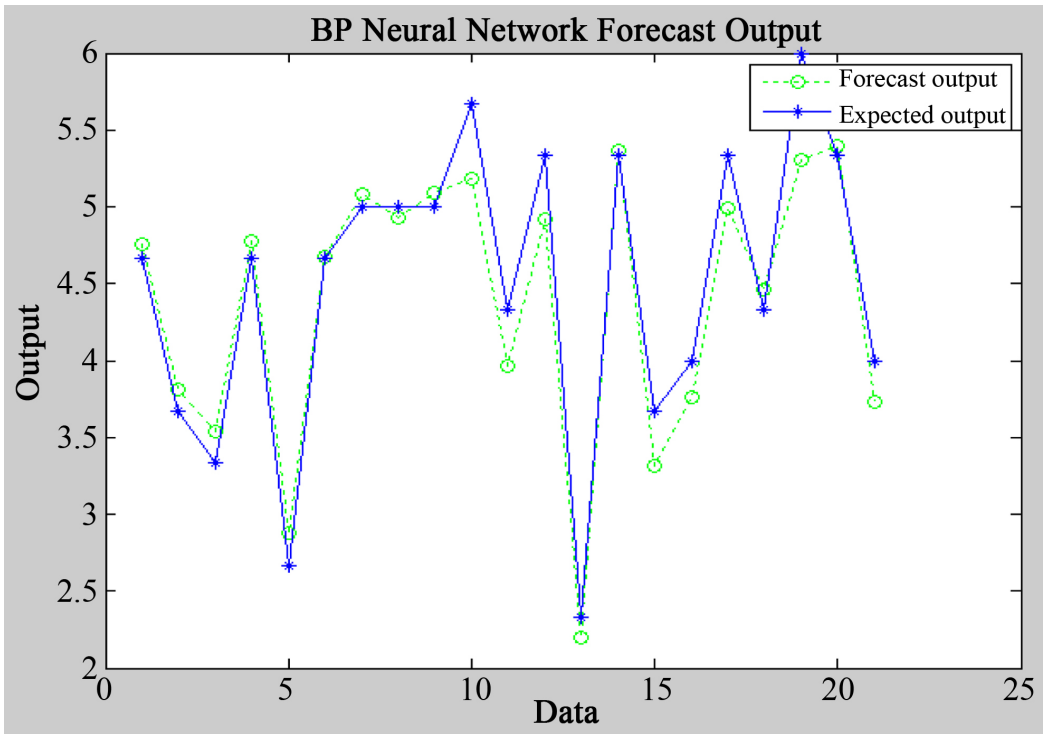

Figure 4. Network forecast output.

The error between the training sample and the test sample is compared as shown in Table 3.

The average error rate of the training sample is $3.22 \%$, and the average error rate of the test sample is $4.90 \%$, both average error rates are low, which means that the accuracy of the model is high. The standard deviation of the training sample is $6.68 \%$ and the standard deviation of the test sample is $7.33 \%$, which shows that the stability of the model is good.

\subsection{Trust Grade Evaluation of Social Commerce}

The output of model-trust degree is a value ranging from 1 to 7 , which is not clear for consumers to judge. In order to further simplify the expression of consumers' trust degree, the trust value can be divided into five grades: complete trust, comparative trust, general, not too much trust, totally not trust. The five trust grades can be respectively represented by $A=\{y \mid 6 \leq y \leq 7\}, B=\{y \mid 4.6 \leq y<6\}, C=\{y \mid 3.3 \leq y<4.6\}$, $D=\{y \mid 2 \leq y<3.3\}$ and $E=\{y \mid y<2\}$. The variable $y$ represents the predicted value of the consumer's comprehensive trust for a social commerce platform.

As a result, the predicted values and the observed values of the 21 test samples are divided into five grades according to the gradation criteria, as shown in Table 4.

It can be seen that the actual output level and expected output level are consistent, which also shows the validity of the trust evaluation model.

\section{Conclusions}

Improving consumers' trust is very important for promoting the socialization of electronic commerce. Trust is a kind of consumer perception that is difficult to be described directly. Based on the research background of social commerce, this paper built up a trust degree evaluation index system that can measure the degree of trust quantita- 
Table 3. Training sample error and test sample error.

\begin{tabular}{ccc}
\hline Error & Training Sample & Testing Sample \\
\hline Average Error & 0.0322 & 0.0490 \\
Standard Deviation & 0.06677 & 0.07334 \\
\hline
\end{tabular}

Table 4. Trust grade of test sample.

\begin{tabular}{cccccccccccccccccccccc}
\hline $\begin{array}{c}\text { Sample } \\
\text { Number }\end{array}$ & 95 & 12 & 143 & 72 & 86 & 127 & 159 & 117 & 190 & 118 & 179 & 20 & 163 & 71 & 85 & 160 & 83 & 33 & 79 & 25 & 51 \\
$\begin{array}{c}\text { Predicted } \\
\text { Output }\end{array}$ & B & C & C & B & D & B & B & B & B & B & C & B & D & B & C & C & B & C & B & B & C \\
$\begin{array}{c}\text { Expected } \\
\text { Output }\end{array}$ & B & C & C & B & D & B & B & B & B & B & C & B & D & B & C & C & B & C & B & B & C \\
\hline
\end{tabular}

tively by some directly measured variables. After a comparative study of existing ecommerce trust evaluation methods, it is found that BP neural network is a good method for data training and simulation of the trust evaluation index system. Model simulation shows that both training data and test data have low level of average error and standard deviation, which certify that the model has good stability and it is a good method for evaluating social commerce trust.

For social commerce websites, a consumer trust evaluation system can help enterprises to intuitively understand what factors enterprises can improve both consumers' trust and their purchase intention, which facilitate to improve service quality. For consumers, a consumer trust evaluation system can help them to know more trust evaluation information from their social friends and social websites, which provide objective reference and recommendations for pleasant online shopping. In the future research, the evaluation model can be applied to the consumer trust evaluation of a social commerce platform to test the actual application effect.

\section{Acknowledgements}

This paper was aided financially by National Science and Technology Support Project "Research on Key Technologies of Collaborative Development of Rural Service Industry" (NO. 2014BAL07B05) and Humanities and Social Science Project of Ministry of Education (NO. 13YJCZH182). The research process was also supported by Beijing Key Laboratory (NO. BZ0211) and Beijing Intelligent Logistics System Collaborative Innovation Center.

\section{References}

[1] China Internet Network Information Center (2016) 2015 China Social Application User Behavior Research Report. http://www.cnnic.net.cn/hlwfzyj/hlwxzbg/sqbg/201604/P020160408334860042447.pdf

[2] Hu, W.X. and Wang, C. (2012) Comparative Study of E-Commerce Trust Evaluation Method. Journal of Modern Information, 11, 3-5.

[3] Jøang, A. (2001) A Logic for Uncertain Probabilities. International Journal of Uncertainty, 
Fuzziness \& Knowledge Based Systems, 9, 279-311.

http://dx.doi.org/10.1142/S0218488501000831

[4] Zhang, J.-A., Zhang, J. and Wang, X.-Y. (2010) Subjective Trust Evaluation Based on Cloud Model Theory for P2P Network. Microelectronics \& Computer, No. 8, 96-99.

[5] Li, Z.-T. and Han, F. (2011) Trust Evaluation Based on Cloud Model for C2C E-Commerce. Information Security and Communications Privacy, No. 2, 74-76.

[6] Fan, L.-J., Wang, S.-Z. and Liu, W. (2012) Evaluation Method Based on Human Trust Mechanism for Mobile E-Commerce Trust. Computer Science, 1, 190-192.

[7] Hu, W.X. and Jiang, Z.J. (2012) A Trust Evaluation Model for C2C E-Commerce Based on BP Neural Network. Library and Information Service, 5, 131-137.

[8] Nick, H. (2015) Social Commerce Constructs and Consumer's Intention to Buy. International Journal of Information Management, No. 35, 183-191. http://dx.doi.org/10.1016/j.ijinfomgt.2014.12.005

[9] Gatautis, R. and Medziausiene, A. (2014) Factors Affecting Social Commerce Acceptance in Lithuania. Social and Behavioral Sciences, 110, 1235-1242. http://dx.doi.org/10.1016/j.sbspro.2013.12.970

[10] Hajli, M. (2013) A Research Framework for Social Commerce Adoption. Information Management \& Computer Security, 3, 144-154. http://dx.doi.org/10.1108/IMCS-04-2012-0024

[11] Harris, L. and Dannis, C. (2011) Engaging Customers on Facebook-Challenges for E-Retailers. Consumer Behavior, 10, 338-346. http://dx.doi.org/10.1002/cb.375

[12] Sherchan, W., Nepal, S. and Paris, C. (2013) A Survey of Trust in Social Networks. ACM Computing Surveys, 45, Article 47. http://dx.doi.org/10.1145/2501654.2501661

[13] Stephen, A.T. and Toubia, O. (2010) Deriving Value from Social Commerce Networks. Journal of Marketing Research, 47, 215-228. http://dx.doi.org/10.1509/jmkr.47.2.215

[14] Liang, T., Ho, Y. and Li, Y. (2012) What Drives Social Commerce: The Role of Social Support and Relationship Quality. International Journal of Electronic Commerce, 16, 69-90. http://dx.doi.org/10.2753/JEC1086-4415160204

\section{Submit or recommend next manuscript to SCIRP and we will provide best service for you:}

Accepting pre-submission inquiries through Email, Facebook, LinkedIn, Twitter, etc.

A wide selection of journals (inclusive of 9 subjects, more than 200 journals)

Providing 24-hour high-quality service

User-friendly online submission system

Fair and swift peer-review system

Efficient typesetting and proofreading procedure

Display of the result of downloads and visits, as well as the number of cited articles

Maximum dissemination of your research work

Submit your manuscript at: http://papersubmission.scirp.org/

Or contact jdaip@scirp.org 